\title{
Viabilidade técnica e econômica de aditivos in situ na digestão anaeróbia de dejetos de bovinos
}

\begin{abstract}
A digestão anaeróbia (DA) é uma técnica notória na destinação dos dejetos do setor da bovinocultura, no entanto, buscam-se métodos de aprimoramento para esse processo. Dessa forma, objetivou-se avaliar o efeito da aplicação direta de biorremediador e amido comercial na DA de dejetos de bovinos leiteiros (DBL) com a finalidade de entender o efeito do biorremediador. Foram, utilizados biodigestores tubulares semicontínuos com volume útil de 60L, com tempo de retenção hidráulica de 30 dias, em temperatura ambiente. Foram avaliados quatro tratamentos com quatro repetições distribuídos em um delineamento inteiramente casualizado, em esquema fatorial 22 representados pelos fatores amido (com e sem aplicação) e biorremediador (com e sem aplicação). Com base nos resultados obtidos dos tratamentos com a aplicação isolada do biorremediador foram definidos cenários em escala real com objetivo biorremediador (com e sem aplicação). Com base nos resultados obtidos dos tratamentos com a aplicação isolada do biorremediador foram definidos cenários em escala real com objetivo reduções de sólidos $(\mathrm{p}<0,05)$ quando comparados ao tratamento sem suas aplicações, entretanto, para a produção especifica de metano por kg de sólidos totais (m3 kgSTadc-1) e voláteis adicionados (m3 kg SVadc-1) a aplicação do biorremediador apresentou melhor resultado $(p<0,05)$. O uso conjunto dos fatores não potencializou o efeito do biorremediador e não se observaram grandes variações nas concentrações de nutrientes no biofertilizante. Dos cenários avaliados, somente o tratamento sem a aplicação do biorremediador demonstrou ser financeiramente atrativo. Embora a DA do DBL tenha sido otimizada com a aplicação do biorremediador, apresentando viabilidade técnica, o uso do aditivo não indicou viabilidade econômica.
\end{abstract}

Palavras-chave: Biorreatores; Economia circular; Energia de fontes alternativas; Enzimas.

\section{Technical and economic feasibility of additives in situ in anaerobic digestion of cattle manure}

\begin{abstract}
Anaerobic digestion (AD) is a notorious technique for the disposal of manure from the cattle industry, however, improvement methods are sought for this process. Thus, the objective was to evaluate the effect of direct application of bioremediation and commercial starch on AD of dairy cattle manure (DCM) with a sense of meaning the effect of the bioremediation. Semicontinuous tubular digesters with a useful volume of $60 \mathrm{~L}$ were used, with hydraulic retention time of 30 days, at room temperature. Four treatments were treated with four repetitions distributed in a completely randomized design, in a factorial scheme 22 represented by the factors starch (with and without application) and bioremediation (with and without application). Based on the results obtained from treatments with the isolation of the bioremediator, they were defined in real scenarios in order to assess the economic viability of the application of the bioremediator. The application of starch and the main bioremediator the highest averages of the potentials of biogas production and reductions in solids ( $p<0.05$ ) when compared to the bioremediator. The application of starch and the main bioremediator the highest averages of the potentials of biogas production and reductions in solids $(p<0.05$ ) when compared to the
treatment without their applications, however, for a specific production of methane per $\mathrm{kg}$ of total solids ( $\mathrm{m} 3 \mathrm{~kg}$-1TSadded) and depreciated volatiles ( $\mathrm{m} 3 \mathrm{~kg}-1 \mathrm{VSadded}$ ) the application of the treatment without their applications, however, for a specific production of methane per $\mathrm{kg}$ of total solids ( $\mathrm{m} 3 \mathrm{~kg}-1 \mathrm{TS}$ added) and depreciated volatiles ( $\mathrm{m} 3 \mathrm{~kg}$ - $1 \mathrm{VSadded}$ ) the application of the
bioremediation has better results $(\mathrm{p}<0.05)$. The combined use of the factors did not enhance the bioremediation effect and there were no large sets of nutrient tools without biofertilizer. Of the adopted scenarios, only the treatment without the application of the exclusive bioremediator would be financially attractive. Although DCM's AD was optimized with the application of the bioremediator, the technical viability, the use of the additive did not indicate economic viability.
\end{abstract}

Keywords: Bioreactors; Circular economy; Energy from alternative sources; Enzymes.

Topic: Desenvolvimento, Sustentabilidade e Meio Ambiente

Reviewed anonymously in the process of blind peer
Received: 01/04/2021

Approved: 28/04/2021
Aline Fernandes (D)

Universidade Estadual Paulista Júlio de Mesquita Filho, Brasil

http://lattes.cnpq.br/4376159254407665

http://orcid.org/0000-0002-1274-6147

aline.nands@hotmail.com

\section{Stela Basso Montoro (ic}

Universidade Estadual Paulista Júlio de Mesquita Filho, Brasil http://lattes.cnpq.br/4504400859902088

http://orcid.org/0000-0002-0739-7798

stela.montoro@unesp.br

Luana Alves Akamine (iD

Universidade Estadual Paulista Júlio de Mesquita Filho, Brasil http://lattes.cnpq.br/2780341257922558

http://orcid.org/0000-0002-4567-2818

luana.a.akamine@gmail.com

\author{
Paula Maria Pilotto Branco (iD \\ Universidade Estadual Paulista Júlio de Mesquita Filho, Brasil \\ http://lattes.cnpq.br/5765907668405091 \\ http://orcid.org/0000-0001-8297-9352 \\ paulapilotto@hotmail.com \\ João Antônio Silva Sousa (D) \\ Universidade Estadual Paulista Júlio de Mesquita Filho, Brasil \\ http://lattes.cnpq.br/1781943305374696 \\ http://orcid.org/0000-0001-8349-7443 \\ joaoantonio.biologo@hotmail.com \\ Jorge de Lucas Júnior (iD \\ Universidade Estadual Paulista Júlio de Mesquita Filho, Brasil \\ http://lattes.cnpq.br/3868629166600922 \\ http://orcid.org/0000-0002-5515-3931 \\ jorge.lucas-junior@unesp.br
}

Referencing this:

FERNANDES, A.; MONTORO, S. B.; AKAMINE, L. A.; BRANCO, P. M. P.; SOUSA, J. A. S.; LUCAS JUNIOR, J.. Viabilidade técnica e econômica de aditivos in situ na digestão anaeróbia de dejetos de bovinos. Revista Ibero Americana de Ciências Ambientais, v.12, n.4, p.530-543, 2021. DOI: http://doi.org/10.6008/CBPC2179-6858.2021.004.0041 


\section{INTRODUÇÃO}

A cadeia produtiva do leite é considerada uma das mais relevantes do agronegócio brasileiro (ROCHA et al., 2018). A destinação dos dejetos dos animais é um ponto crítico da bovinocultura leiteira, considerando que práticas inadequadas desencadeiam em riscos à saúde pública e impactos ambientais (CHEN et al., 2019).

Paralelamente a problemática ambiental, outro ponto a ser considerado é a adoção de novas tecnologias que trazem maior dependência de energia elétrica, demandada para o acionamento de diversos equipamentos (PERAZZOLI et al., 2018).

O manejo dos resíduos por meio da digestão anaeróbia (DA) é imprescindível, posto que é um processo biológico que propicia simultaneamente: (1) o tratamento dos resíduos orgânicos, reduzindo a capacidade poluente que possuem, (2) a redução as emissões de gases de impacto no efeito estufa, de modo direto, por evitar as emissões da decomposição natural do dejeto no ambiente, ou de modo indireto, quando o biogás gerado substitui o uso de combustíveis fósseis e (3) a produção do biofertilizante, recurso valioso e estratégico como insumo agrícola de baixo custo (KAUFMANN, 2015; NESHAT et al., 2017; SCARLAT et al., 2018).

Desse modo, o aproveitamento dos produtos da DA, isto é, o biofertilizante e o biogás, proporciona valor econômico para as diversas cadeias do agronegócio, de pequeno a grande porte, devido a menor dependência dos fertilizantes minerais e o aumento da autossuficiência energética (FERNANDES FILHO, 2018; MONTORO et al., 2019).

Nas propriedades com confinamento de bovinos leiteiros, a viabilidade econômica da implantação de biodigestores é fundamentada no rendimento energético recuperado, fato que ressalta a necessidade de aplicação de técnicas para potencializar o rendimento de biogás e metano desses dejetos. A separação da fração sólida da fração líquida dos dejetos de bovinos é uma técnica comumente aplicada, visto que a DA dos dejetos de bovinos, nas condições naturais, pode acarretar em redução do seu aproveitamento energético, em razão do alto teor de sólidos totais (40-50\%) e composição fibrosa (IMENI et al., 2020; ZULKIFLI et al., 2015; MARAÑóN et al., 2012; ANGELIDAKI et al., 2005).

As técnicas de pré-tratamentos (térmico, mecânico, químico, físico e biológico), codigestão, aplicação de aditivos orgânicos, entre outras, são alternativas para a DA de substratos mais complexos. No entanto, a seleção dessas técnicas deve ser criteriosa, pois as técnicas que requerem altas cargas de energia podem ocasionar desequilíbrio energético. Além do mais suas aplicações, em larga escala, devem ser ponderadas aos custos necessários com equipamentos extras e produtos, e problemas com segurança dos trabalhadores (MAGDALENA et al., 2018; ZHANG et al., 2018).

A aplicação direta de enzimas é uma técnica atrativa, principalmente, por as enzimas serem inóxias aos microrganismos anaeróbios e por não requerer equipamentos extras, o que leva a menor complexidade e menor custo de operação (BRÉMOND et al., 2018; BRAVO et al., 2013; ROMANO et al., 2009).

De acordo com diversos autores, os dejetos de bovinos leiteiros codigeridos com culturas energéticas, e a aplicação de pré-tratamentos, indicam efeito positivo sobre a produção de biogás e metano 
(MONTORO et al., 2019; ŞENOL et al., 2019; VIEIRA et al., 2015; KALAMARAS et al., 2014). Desse modo, é possível inferir que a aplicação do amido comercial como aditivo na DA de dejeto bovino ocasionará efeitos semelhantes aos obtidos quando esse é codigerido com culturas amiláceas de potencial energético e, assim, permitir a avaliação do efeito do biorremediador testado sobre esses substratos codigeridos.

Contudo, de acordo com a literatura consultada, há poucos estudos sobre a aplicação direta de biorremediador na digestão anaeróbia de dejetos de bovinos leiteiros. Além do mais, falta informações da submissão dos resultados técnicos à análise de viabilidade econômica.

Uma vez que, os indicadores econômicos são essenciais para a tomada de decisão assertiva, o uso de enzimas comerciais deve ser considerado viável ao processo anaeróbio quando atender as questões de viabilidade técnica e econômica (REGERT et al., 2018; GÜIZA et al., 2016; ZHENG et al., 2014).

Diante do exposto, neste trabalho objetivou-se avaliar a viabilidade técnica e econômica do uso do biorremediador na produção de biogás e do teor de metano de dejetos bovinos leiteiros.

\section{MATERIAIS E MÉTODOS}

\section{Descrição do ensaio}

O substrato utilizado foi dejeto de bovinos leiteiros (DBL) provenientes de vacas da raça Holandesa, coletado semanalmente nas instalações do sistema de semiconfinamento nas dependências da Universidade Estadual Paulista/UNESP - FCAV, Campus de Jaboticabal, no Departamento de Zootecnia do Setor de Bovinocultura. O material foi transportado para o Departamento de Engenharia Rural até ao Laboratório de Digestão Anaeróbia, onde a pesquisa foi conduzida.

O DBL foi diluído em água, considerando-se $6 \%$ de sólidos totais (ST). Em seguida, o DBL diluído foi submetido a um pré-tratamento mecânico, no qual, por meio de uma peneira de malha de $2 \mathrm{~mm}$, retirou-se o material de maior diâmetro, o qual foi retornado ao setor de Bovinocultura para ser destinado a leira de compostagem do setor. O material que passou pela peneira foi utilizado como substrato base para a composição dos tratamentos do experimento.

Foram utilizados dois aditivos: (1) o biorremediador composto por um complexo enzimático: amilase, celulase, pectinase, fitase, lipase e protease; e pôr probióticos: Lactobacilos Acidófilos, Bifidobacterium Longum, Bifidobacterium Thermophilum e Bacillus Subtilis liofilizados em maltodextrina. (2) o amido comercial com a finalidade de avaliar do efeito da aplicação do biorremediador na DA do DBL em codigestão com cultura energética amilácea, tomando como pressuposto o amido como carboidrato presente em maior proporção na composição dessas culturas com potenciais energéticos (SILVA et al., 2000). Esses aditivos foram aplicados após a preparações das cargas diárias (CD) do substrato e essas conduzidas imediatamente aos abastecimentos dos biodigestores.

O delineamento estatístico utilizado foi inteiramente casualizado, em esquema fatorial $2^{2}$, os quais consistiam na aplicação do biorremediador (sem e com aplicação) e na aplicação do amido (sem e com aplicação). 
O início do ensaio deu-se com o abastecimento total dos 16 biodigestores com o substrato base, (DBL diluído e peneirado). Posteriormente foram realizadas cargas diárias $(2,0 \mathrm{~L})$ com composição semelhante ao substrato base, durante um tempo de retenção hidráulica (TRH) de 30 dias, com a finalidade de adaptação dos microrganismos anaeróbios ao meio obtenção da produção de biogás padronizada. Após deu-se início a aplicação dos aditivos.

O ensaio foi dividido em quatro tratamentos, designados da seguinte maneira: SASB (sem amido e sem biorremediador), CASB (com amido e sem biorremediador), SACB (sem amido e com biorremediador) e CACB (com amido e com biorremediador) (Tabela 1). Os digestores foram operados por 30 dias em temperatura ambiente aferida diariamente apresentando leves oscilações sendo: a média $27,32^{\circ} \mathrm{C}$, a mínima $22,10^{\circ} \mathrm{C}$ e a máxima $31^{\circ} \mathrm{C}$, permanecendo durante todo o ensaio na faixa mesofílica (20 a 45 o $\mathrm{C}$ ) (CHERNICHARO, 2007).

Tabela 1: Composição dos substratos dos tratamentos avaliados.

\begin{tabular}{lllll}
\hline Tratamentos & Dejeto Bovino $(\mathrm{kg})$ & Água $(\mathrm{kg})$ & Amido comercial $(\mathrm{kg})$ & Biorremediador $(\mathrm{mL})$ \\
\hline SASB & 0,5 & 1,5 & 0 & 0 \\
CASB & 0,5 & 1,5 & 0,025 & 0 \\
SACB & 0,5 & 1,5 & 0 & 1,0 \\
CACB & 0,5 & 1,5 & 0,025 & 1,0 \\
\hline
\end{tabular}

O digestor consiste uma câmera de fermentação em policloreto de vinilha (PVC) com capacidade total de 60 litros, sendo formada por um tubo de $1 \mathrm{~m}$ de comprimento e $30 \mathrm{~mm}$ de diâmetro com essas extremidades vedadas por cap de PVC contendo abertura com um tubo para entrada do substrato e na extremidade oposta um outro tubo conectado a um registro para saída do biofertilizante. O biogás gerado foi conduzido por mangueira de silicone para o gasômetro, esse confeccionado por dois tubos de $60 \mathrm{~cm}$ de comprimento e diâmetros de $230 \mathrm{~mm}$ e $300 \mathrm{~mm}$, esse último fixado em CAP de PVC preenchido com água e o tubo de diâmetro menor submerso nesta água para mensurar os deslocamentos causados pelo gás, com uma das extremidades vedada por outro CAP de PVC com abertura para um registro que permite a liberação para coleta ou a queima do biogás. Na parede externa do gasômetro foi fixada uma régua graduada de 50 cm para auxiliar na mensuração dos deslocamentos.

\section{Métodos Analíticos}

As amostras foram submetidas as análises semanais de sólidos totais (ST) determinado pela secagem em estufa a $105{ }^{\circ} \mathrm{C}$ por $24 \mathrm{~h}$, de sólidos voláteis (SV) por meio da determinação do teor de cinzas pela combustão das amostras secas em $550^{\circ} \mathrm{C}$ por $5 \mathrm{~h}$, de acordo com os Métodos Padrão (APHA, 2005), o teor de Nitrogênio Total Kjeldahl (NTK) foi determinado de acordo com metodologia descrita por Silva et al. (2000), a determinação do fósforo (P) de acordo com a metodologia de Malavolta et al. (1997) determinado pelo método colorimétrico detectado via absorbância por meio de um espectrofotômetro Hach ${ }^{\circledR}$ (modelo Dr-2000), e o potássio (K) pela submissão das amostras a digestão nítrico-perclórica, seguida de diluição e filtração e suas concentrações determinadas em espectrofotômetro de absorção atômica (modelo GBC 932 $A A)$. 
A produção de biogás foi realizada por registros diários do deslocamento vertical do gasômetro e temperatura ambiente e após padronizada conforme as condições normais de temperatura e pressão. 0 teor de metano $\left(\mathrm{CH}_{4}\right)$ foi determinado semanalmente por cromatografia gasosa (Tracera- CG-2010 Plus), para tanto as amostras foram colhidas em seringas e imediatamente injetadas no cromatógrafo, equipado com um detector de ionização por plasma (BID-2010 Plus), utilizando hélio como gás de arraste em coluna Carboxen ${ }^{\circledast} 1010$ Plot. As eficiências de remoção de ST e SV foram calculadas a partir das concentrações iniciais (antes da digestão anaeróbia) e finais (depois da digestão anaeróbia). A produção de biogás e $\mathrm{CH}_{4} \mathrm{e}$ as concentrações de ST e SV foram usadas para determinar os potenciais específicos de produção de biogás $\left(\mathrm{m}^{3} \mathrm{~kg}^{-1}\right)$ e de $\mathrm{CH}_{4}\left(\mathrm{~m}^{3} \mathrm{~kg}^{-1}\right)$.

\section{Análise estatística}

Todas as variáveis foram analisadas com base nas repetições (quatro repetições por tratamento). Após verificação do atendimento aos pressupostos os dados foram submetidos a análise de variância (ANOVA), seguido pelo teste de Tukey com 5\% de significância.

Foi aplicada a técnica multivariada de análises de componentes principais (ACP) sobre as variáveis. Os componentes principais foram selecionados pelo critério dos autovalores maiores que a unidade $(\lambda>1)$ (KAISER, 1958).

\section{Análise de viabilidade econômica}

A viabilidade econômica foi proposta para avaliar os cálculos dos investimentos necessários para implementar um biodigestor, considerando os produtos finais da DA (biogás e biofertilizante) como receitas, os custos de manutenção e operação do biodigestor, no horizonte de planejamento de 10 anos.

Para definir os cenários econômicos utilizou-se, os resultados do potencial de produção de biogás por sólidos totais adicionados e os teores de N, P e K, referente aos tratamentos de interesse, assim os cenários foram definidos em: sem aplicação do biorremediador (SB) e com aplicação do biorremediador (CB), sendo que para cada cenário foram adotadas: 200 vacas em lactação confinadas e produção diária de $30 \mathrm{~kg}$ de dejeto.

Os custos operacionais de cada projeto foram compostos por: o investimento inicial considerando as aquisições de equipamentos e materiais para a implantação do biodigestor, bem como, o grupo motogerador instalado na rede de transmissão de energia elétrica, aquisição do biorremediador, manutenção dos biodigestores e geradores, remuneração do trabalhador rural e com equipamentos de proteção individual, depreciação dos equipamentos e tributos, com alíquota de $24 \%$, segunda a base de cálculo por Lucro Real.

Para calcular a receita de energia elétrica gerada, por meio dos resultados do potencial de produção de biogás por sólidos totais adicionados, foi adotada a média das tarifas de energia elétrica de $\mathrm{R} \$ 0,40$ centavos por kWh com impostos, correspondentes a categoria "consumidor do Grupo B2/Convencional Rural" cobrada pelas distribuidoras de energia do país no primeiro semestre de 2020 (ANEEL, 2020).

Para calcular a receita do biofertilizante produzido foi considerado $100 \%$ o seu aproveitamento, na 
adubação de culturas produzidas para compor as dietas das vacas, gerando uma economia na aquisição de fertilizantes minerais. O cálculo foi realizado a partir de sua composição química (macronutrientes primários) com equivalência aos adubos comerciais (sulfato de amônio: $21 \%$ de N; superfosfato simples: $18 \%$ de $\mathrm{P}_{2} \mathrm{O}_{5}$ e cloreto de potássio: $60 \% \mathrm{~K}_{2} \mathrm{O}$ ). Considerou-se o valor de acordo com cotação direta com empresa especializada em vendas, de acordo com o mercado em fevereiro de 2020.

Os fluxos de caixa livre dos projetos foram descontados a uma taxa mínima de atratividade de 4,15\%, referente a taxa básica de juros da economia brasileira (SELIC), em fevereiro de 2020.

A partir dos custos e benefícios obtidos foi possível definir o fluxo de caixa descontado do projeto, e assim realizar a análise viabilidade econômica a partir dos indicadores: Taxa Interna de Retorno (TIR), Valor Presente Líquido (VPL), Índice de Lucratividade (IL), Tempo de recuperação do investimento (Payback) (GRAHAM et al., 2001; MONTORO et al., 2019):

$$
V P L=\sum_{t=1}^{n} \frac{F C L_{t}}{(1+K)^{t}}-F C_{0}
$$

Em que:

FCLt é o fluxo de caixa de cada período; K é a taxa de desconto de projeto, representada pela rentabilidade mínima requerida; FCO é o Investimento processado no momento zero.

$$
\mathrm{MO}=\sum_{t=1}^{0} \frac{F C L}{(1+T I R)^{t}}-F C_{0}
$$

Em que:

M0 é o investimento no momento zero (início do projeto); FCLt são os montantes previstos de investimento em cada momento subsequente; TIR é a taxa de rentabilidade equivalente periódica.

$$
\boldsymbol{I L}=\frac{\sum_{t=1}^{n} \frac{F C L_{t}}{(1+K)^{t}}}{I}
$$

Em que:

IL é o índice de Lucratividade; FCL é o fluxo de caixas; I é o investimento.

\section{RESULTADOS E DISCUSSÃO}

A Tabela 2 apresenta o resumo da análise de variância dos dados obtidos referentes as variáveis analisadas de potenciais de produção, teor de metano e reduções de sólidos. Nota-se que essas variáveis apresentam diferença significativa, afirmando a hipótese de a aplicação dos aditivos terem influência sobre o processo de DA.

Houve efeito principal $(p<0,05)$ do fator amido e fator amido sobre as variáveis Biogás $\left(m^{3}\right)$, Biogás $\left(\mathrm{m}^{3} \mathrm{~kg}_{\text {stadc }}{ }^{-1}\right)$, Biogás $\left(\mathrm{m}^{3} \mathrm{~kg}_{\text {svadc }}{ }^{-1}\right)$, Metano $\left(\mathrm{m}^{3} \mathrm{~kg}_{\text {stadc }}{ }^{-1}\right)$, Metano $\left(\mathrm{m}^{3} \mathrm{~kg}_{\mathrm{svadc}}{ }^{-1}\right)$ e do fator biorremediador sobre Biogás $\left(\mathrm{m}^{3}\right)$, Biogás $\left(\mathrm{m}^{3} \mathrm{~kg}_{\text {stadc }}{ }^{-1}\right)$, Biogás $\left(\mathrm{m}^{3} \mathrm{~kg}_{\mathrm{svadc}}{ }^{-1}\right)$. Os tratamentos com aplicação do amido ou do biorremediador para a produção de biogás e demais potenciais de produção analisados que apresentaram diferença significativa $(p<0,05)$ tiveram as maiores médias de produção quando comparados aos tratamentos que não receberam suas aplicações (Tabela 3). 
Tabela 2: Resumo da análise de variância (valor de p) da produção total de biogás $\left(\mathrm{m}^{3}\right)$, metano $\left(\mathrm{m}^{3}\right)$, sólidos totais adicionados $\left(\mathrm{ST}_{\mathrm{adc}}\right)$, sólidos voláteis adicionados $\left(\mathrm{SV}_{\mathrm{adc}}\right)$, produção de biogás e metano por kg de sólidos totais $\left(\mathrm{m}^{3} \mathrm{~kg} \mathrm{sTadc}^{-}\right.$ $\left.{ }^{1}\right)$ e voláteis adicionados $\left(\mathrm{m}^{3} \mathrm{kgsvadc}^{-1}\right)$.

\begin{tabular}{llll}
\hline FV & Biogás $\left(\mathrm{m}^{3}\right)$ & $\begin{array}{l}\text { Biogás } \\
\left(\mathrm{m}^{3} \mathrm{~kg}_{\mathrm{STadc}}{ }^{-1}\right)\end{array}$ & $\begin{array}{l}\text { Biogás } \\
\left(\mathrm{m}^{3} \mathrm{~kg}_{\mathrm{SVadc}}{ }^{-1}\right)\end{array}$ \\
\hline Amido (A) & $<0,0001^{*}$ & $<0,0001^{*}$ & $<0,0001^{*}$ \\
Biorremediador (B) & $0,0443^{*}$ & $0,0299^{*}$ & $0,0348^{*}$ \\
AxB & 0,3139 & 0,9871 & 0,8370 \\
$\mathrm{CV}(\%)$ & 6,44 & 6,45 & 6,44 \\
\hline FV & Metano $\left(\mathrm{m}^{3}\right)$ & Metano & Metano \\
& & $\left(\mathrm{m}^{3} \mathrm{~kg}_{\mathrm{STadc}}{ }^{-1}\right)$ & $\left.<\mathrm{kg}_{\mathrm{sVadc}}^{-1}\right)$ \\
\hline Amido (A) & 0,1045 & $<0,0001^{*}$ & $<0,0001^{*}$ \\
Biorremediador (B) & 0,1016 & 0,0635 & 0,0691 \\
AxB & $<0,0001$ & 0,5956 & 0,0591 \\
CV (\%) & 5,58 & 6,95 & 6,97 \\
\hline
\end{tabular}

*Significativo ao nível de $5 \%$ de probabilidade pelo teste de Tukey.

Tabela 3: Efeito principal da aplicação amido e biorremediador para produção total $\left(\mathrm{m}^{3}\right)$ e produção específica de biogás e metano por $\mathrm{kg}$ de sólidos totais $\left(\mathrm{m}^{3} \mathrm{~kg}_{\mathrm{sTadc}}{ }^{-1}\right)$ e sólidos voláteis adicionados $\left(\mathrm{m}^{3} \mathrm{~kg}_{\mathrm{svadc}}{ }^{-1}\right)$.

\begin{tabular}{|c|c|c|c|c|}
\hline \multirow{2}{*}{ Variáveis } & \multicolumn{2}{|l|}{ Amido } & \multicolumn{2}{|c|}{ Biorremediador } \\
\hline & Sem & Com & Sem & Com \\
\hline Produção diária $\left(\mathrm{m}^{3}\right.$ dia $\left.^{-1}\right)$ & $526,5 b$ & $857,0 a$ & $666,9 b$ & $716,9 a$ \\
\hline Biogás $\left(\mathrm{m}^{3} \mathrm{~kg}_{\mathrm{sTadc}}{ }^{-1}\right)$ & $323,0 b$ & $533,7 a$ & $411,3 b$ & $445,4 a$ \\
\hline Biogás $\left(\mathrm{m}^{3} \mathrm{~kg}_{\mathrm{svadc}}{ }^{-1}\right)$ & $385,4 b$ & $636,2 a$ & $491,4 b$ & $530,2 a$ \\
\hline Metano $\left(\mathrm{m}^{3} \mathrm{~kg}_{\text {stadc }}{ }^{-1}\right)$ & $212,3 b$ & $301,9 a$ & $237,0 a$ & $290,0 a$ \\
\hline Metano $\left(\mathrm{m}^{3} \mathrm{~kg}_{\text {svadc }}{ }^{-1}\right)$ & $252,8 b$ & $359,4 a$ & $283,0 a$ & $344,5 a$ \\
\hline
\end{tabular}

*Médias seguidas por letras distintas, minúsculas na linha e dentro de cada fator, diferem entre si pelo teste Tukey $(P \leq 0,05)$.

A menor produção de biogás e as demais variáveis analisadas com resultados inferiores apresentadas pelo tratamento SASB em relação aos demais tratamentos, isto é, com a aplicação do amido ou do biorremediador, mostra que mesmo após o dejeto de bovino ser submetido ao pré-tratamento mecânico ainda apresenta características a serem alteradas, portanto, ocorreu melhor eficiência no processo pela aplicação conjunta de pré-tratamento e aditivos (ZHANG et al., 2018).

Quando produtos comerciais enzimáticos são aplicados em material lignocelulósico melhores condições são oferecidas ao processo, de tal modo maior eficácia é provocada na fase hidrolítica (ROMANO et al., 2009). Assim, a relação positiva da aplicação do biorremediador utilizado neste experimento e a não aplicação, sobre o desempenho da DA é pertinente, pois em síntese, o dejeto bovino é composto, principalmente, por proteínas e biomassa lignocelulósica não digerida pelo animal (BRÉMOND et al., 2018).

Gerhardt et al. (2007) e Hölker (2008) estudaram a aplicação direta de enzimas em usinas de biogás abastecidas com dejeto bovino e outros substratos e obtiveram ganhos na produção de biogás. Resultados semelhantes foram encontrados por Speda et al. (2017) no qual constataram efeito significativo da adição direta de uma mistura de enzimas celulolíticas na DA de silagem sobre a produção de biogás devido a solução enzimática ter degradado o material celulósico menos acessível as bactérias naturais do processo.

Os resultados do presente estudo, de maneira geral, indicam que o tratamento com a aplicação conjunta de amido e biorremediador (CACB) apresentaram a mesma eficiência de produção quando comparados aos que tiveram as aplicações isoladas desses fatores.

Esse desempenho é semelhante com o encontrado por Garcia et al. (2019), que relataram que as aplicações de enzimas comerciais em biodigestores abastecidos com substratos com alto teor de lignina 
apresentaram efeitos relevantes positivos, ao passo que para substratos facilmente degradáveis, os ricos em açúcares, não apresentou efeito. E inferem que o resultado encontrado por eles está relacionado com a alta degradabilidade natural de culturas energéticas, como grãos de milho e triticale.

Houve interação $(p<0,05)$ entre os fatores amido versus biorremediador para as variáveis sólidos totais reduzidos ( $\mathrm{ST}_{\text {red }}$ ), sólidos voláteis reduzidos ( $\mathrm{SV}_{\text {red }}$ ) e $\mathrm{CH}_{4}$ (\%) (Tabela 4). Para as variáveis de $\mathrm{ST}_{\text {red }}$ e $\mathrm{CH}_{4}$ (\%) o tratamento SACB apresentou maior redução e maior teor $\mathrm{CH}_{4}(\%)$ quando comparado ao tratamento CACB e para a variável $S V_{\text {red }}$ o tratamento $S A C B$ e o CASB não diferiu do tratamento $C A C B$. A interação entre os fatores para essas variáveis não foi favorável, já que as reduções de sólidos e o teor de $\mathrm{CH}_{4}$ não obtiveram efeitos melhores ao aplicar o biorremediador sobre o amido.

Tabela 4: Desdobramento da aplicação do amido com a aplicação do biorremediador para $\mathrm{CH}_{4}(\%)$, sólidos totais (STred) e sólidos voláteis reduzidos ( $S V_{\text {red }}$ ).

\begin{tabular}{llll}
\hline \multirow{2}{*}{ Variável } & \multirow{2}{*}{ Amido } & Biorremediador & \\
\cline { 3 - 4 } & & Sem & Com \\
\hline \multirow{2}{*}{$\mathrm{ST}_{\text {red }}(\%)$} & Sem & $55,38 \mathrm{Bb}$ & $74,73 \mathrm{Aa}$ \\
$\mathrm{SV}_{\text {red }}(\%)$ & Com & $68,53 \mathrm{Aa}$ & $60,42 \mathrm{Ba}$ \\
& Sem & $61,28 \mathrm{Bb}$ & $76,57 \mathrm{Aa}$ \\
& Com & $70,95 \mathrm{Aa}$ & $66,32 \mathrm{Aa}$ \\
$\mathrm{CH}_{4}(\%)$ & & & \\
& & $57,50 \mathrm{Ab}$ & $66,30 \mathrm{Aa}$ \\
& Cem & $60,45 \mathrm{Aa}$ & $58,73 \mathrm{Ba}$ \\
\hline
\end{tabular}

*Médias seguidas por letras distintas, maiúscula na coluna e minúscula na linha, diferem entre si pelo teste Tukey $(P \leq 0,05)$.

O SV é definido como parte da matéria orgânica presente no substrato passível de degradação, sendo a parte que as bactérias metanogênicas utilizam como substrato para a conversão em biogás (COSTA et al., 2013). Desse modo, para determinar a eficiência do pré-tratamento dos dejetos bovinos não só a taxa de produção de biogás deve ser considerada, mas a taxa de $S V_{\text {red }}($ GABALLAH et al., 2020), no presente estudo consideramos a eficiência da aplicação direta do fator amido e biorremediador e suas interações, nos quais observamos os melhores resultados para a aplicação de cada um dos aditivos em relação aos que não receberam nenhum deles e nem de forma conjunta.

Enquanto a biomassa agrícola amilácea apresenta desempenho hábil por ter fácil biodegradabilidade, o contrário acontece com a biomassa lignocelulósica devido à resistência à hidrólise (TEGHAMMA et al., 2012). O alto teor de fibras do DBL faz com que as reduções de sólidos fiquem entre 4050\% (BRUNI et al., 2010). O que pode ser influenciado com o uso de enzimas por proporcionarem maiores rendimentos de açúcares fermentáveis (BRIJWANI et al., 2010). Condições essas que podem ser atribuídas aos resultados de $\mathrm{ST}_{\text {red }}$ e $\mathrm{ST}_{\text {red }}$ dos tratamentos que receberam o amido ou biorremediador neste experimento.

Brémond et al. (2018) estudaram a adição direta da enzima amilase na DA o que rendeu um aumento de metano em $111 \%$. Os autores relataram que esse resultado é devido à interferência positiva que as enzimas como: celulases, hemicelulases, amilases e pectinases, também encontradas no biorremediador aplicado neste experimento, se bem aplicadas apresentam ao processo.

Em relação as concentrações dos macronutrientes ( $N, P$ e K) determinadas no biofertilizante houve 
interação significativa $(p<0,05)$ entre os fatores amido e biorremediador sobre os teores de nitrogênio $(N)$ e fósforo $(P)$ e efeito principal $(p<0,05)$ do fator biorremediador somente sobre o teor de potássio $(K)$ (Tabela 5). O biofertilizante que resultou dos biodigestores que recebeu o biorremediador apresentaram maior concentração de K (Tabela 6).

Tabela 5: Resumo da análise de variância do teor de nitrogênio (N), fósforo $(P)$ e potássio (K)

\begin{tabular}{llll}
\hline FV & $\mathrm{N}$ & $\mathrm{P}$ & $\mathrm{K}$ \\
\hline Amido (A) & $<0,0001^{*}$ & $<0,0001^{*}$ & 0.7839 \\
Biorremediador (B) & $<0,0001^{*}$ & $<0,0001^{*}$ & $0,0473^{*}$ \\
$\mathrm{AxB}$ & $<0,0001^{*}$ & $<0,0001^{*}$ & 0,6928 \\
\hline $\mathrm{CV}(\%)$ & 1,07 & 2,66 & 13,12 \\
\hline
\end{tabular}

*Significativo ao nível de $5 \%$ de probabilidade pelo teste de Tukey.

Tabela 6: Efeito principal da aplicação amido e biorremediador para potássio (K).

\begin{tabular}{llllll}
\hline \multirow{2}{*}{ Variáveis } & \multicolumn{2}{l}{ Amido } & & \multicolumn{2}{l}{ Biorremediador } \\
\cline { 2 - 3 } \cline { 5 - 6 } & Sem & Com & Sem & Com \\
\hline $\mathrm{K}$ & 2,66 & 2,73 & & $2,41 \mathrm{~b}$ & $2,97 \mathrm{a}$ \\
\hline
\end{tabular}

$a-b$ : Médias seguidas de letras distintas na linha diferem entre si pelo teste de Tukey $(p<0,05)$

Para o nutriente $\mathrm{N}$ o tratamento CASB e SACB apresentaram médias maiores que o tratamento CACB, sendo a interação não positiva. Comportamento contrário esses tratamentos apresentaram para o nutriente P, sendo a interação para essa variável favorável, já que a aplicação do amido aumentou o teor desse nutriente. (Tabela 7).

Tabela 7: Desdobramento da aplicação do amido com a aplicação do biorremediador para nitrogênio (N) e fósforo (P).

\begin{tabular}{llll}
\hline \multirow{2}{*}{ Variáveis } & \multirow{2}{*}{ Amido } & \multicolumn{3}{l}{ Biorremediador } & Com \\
\cline { 3 - 4 } & & Sem & $3,49 \mathrm{Aa}$ \\
$\mathrm{N}$ & Sem & $3,12 \mathrm{Bb}$ & $3,35 \mathrm{Bb}$ \\
& $\mathrm{Com}$ & $4,45 \mathrm{Aa}$ & $2,02 \mathrm{Ba}$ \\
$\mathrm{P}$ & Sem & $1,98 \mathrm{Aa}$ & $2,22 \mathrm{Aa}$ \\
\hline
\end{tabular}

*Médias seguidas por letras distintas, maiúscula na coluna e minúscula na linha, diferem entre si pelo teste Tukey $(\mathrm{P} \leq 0,05)$.

A obtenção de um efluente, ou seja, do biofertilizante com alta qualidade está relacionado com a capacidade do processo degradar compostos orgânicos complexos, por ocasionar maior eficiência na remoção de matéria orgânica (CAMMAROTA et al., 2006).

Os resultados mostram que os teores dos macronutrientes primários analisados no substrato se apresentaram abaixo do que os encontrados após a DA, ou seja, no biofertilizante. Isso ocorre pelo fato que no processo de DA há perdas de carbono como na forma de $\mathrm{CH}_{4}$ e $\mathrm{CO}_{2}$, resultando a concentração de outros nutrientes (PRAES et al., 2015).

A Figura 1 mostra a ACP, em que os dois primeiros componentes principais foram responsáveis por $76,4 \%$ da variação total, sobre a eficiência da DA dos tratamentos avaliados no ensaio semicontínuo, em que o CP1 explica 51,9\% e o CP2 explica $24,5 \%$ das variações dos dados.

A correlação positiva entre as variáveis produção de biogás $\left(\mathrm{m}^{3}\right)$, potenciais de produção de biogás e metano ( $\left.\mathrm{m}^{3} \mathrm{~kg}_{\mathrm{STadc}}{ }^{-1}, \mathrm{~m}^{3} \mathrm{~kg}_{\mathrm{Svadc}}{ }^{-1}\right)$, teor de $\mathrm{CH}_{4}(\%)$ e nitrogênio total Kjeldahl ( $\left.\mathrm{N}\right)$, apresentadas no CP1 são responsáveis pela discriminação dos tratamentos CASB e CACB, localizados à direita do componente.

$\mathrm{O}$ CP2 apresentou correlação positiva com o teor $\mathrm{CH}_{4}(\%)$ situado no quadrante superior esquerdo 
próximo ao tratamento $\mathrm{SACB}$ que foi o tratamento que apresentou o maior teor de $\mathrm{CH}_{4}$ (Figura 9).

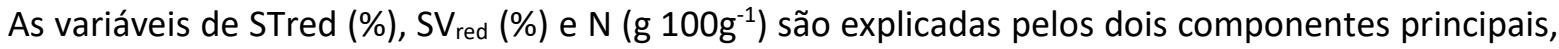
discriminando os tratamentos CASB, SACB e CACB.

A correlação positiva entre as variáveis de potenciais de produção $\left(\mathrm{m}^{3}\right)$, reduções de sólidos (\%) e do teor de nutrientes (g $100 \mathrm{~g}^{-1}$ ) estão relacionadas a melhor biodegradabilidade do substrato e a eficiência da digestão, nos quais são responsáveis pelo agrupamento dos tratamentos que receberam a aplicação direta do amido e/ou do biorremediador e o isolamento à esquerda do CP1 e na parte inferior do CP2, do tratamento SASB, ou seja, o tratamento que não recebeu nenhum dos aditivos, o que justifica a necessidade do dejeto bovino leiteiro ser submetido a técnica de pré-tratamento e aplicação direta de aditivos.

Visto que o dejeto de bovino leiteiro é, sem dúvidas, promissor para o processo anaeróbio, porém por apresentar no teor de sólidos totais material fibroso de difícil degradação faz com que o rendimento de biogás seja reduzido (ZULKIFLI et al., 2015).

Dessa forma, a maior produção de biogás $\left(\mathrm{m}^{3}\right)$ nos biodigestores conduzidos com aplicação fator amido e biorremediador em comparação aos que não tiveram a aplicação, parece caracterizar, à primeira vista, que houve melhor degradabilidade proporcionada pelo amido e que também houve um suprimento às bactérias hidrolíticas que receberam enzimas extras constituintes do biorremediador. Visto que, as enzimas aplicadas na DA assumem a função de favorecer o desenvolvimento dos diferentes microrganismos envolvidos na degradação da biomassa e, portanto, permite o uso de substratos mais resistentes ao processo anaeróbio (ZHENG et al., 2014).

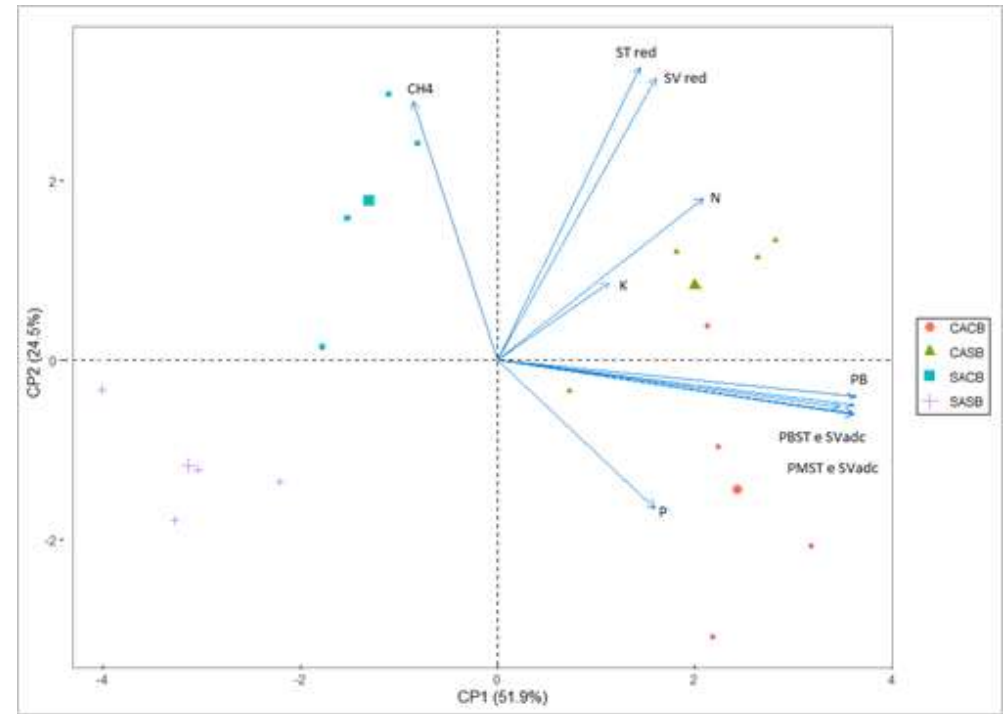

Figura 1: Gráfico biplot da ACP das variáveis analisadas sobre o desempenho da DA de dejetos bovinos com a aplicação direta dos aditivos.

A Tabela 8 apresenta a média obtida do fluxo de caixa da análise econômica, do período de 10 anos, desenvolvida para os cenários SB (sem aplicação do biorremediador) e CB (com aplicação do biorremediador).

A média das receitas no período de 10 anos estimadas nos projetos, nos demonstram que, o aumento de biogás proporcionado pela utilização do biorremediador nos biodigestores permitiu um aumento de 15,23 
\%, em relação ao cenário que não utiliza o produto.

Tabela 8: Fluxo de caixa para os cenários analisados

\begin{tabular}{lll}
\hline & $\mathrm{SB}$ & $\mathrm{CB}$ \\
\hline Receita total & $\mathbf{1 4 8 . 9 8 5 , 3 2}$ & $\mathbf{1 6 6 . 9 0 0 , 8 7}$ \\
\hline Energia elétrica & $91.645,19$ & $101.891,24$ \\
Biofertilizante & $57.340,13$ & $65.009,63$ \\
\hline Investimento inicial & $\mathbf{3 4 2 . 5 2 1 , 5 8}$ & $\mathbf{3 4 2 . 5 6 1 , 5 8}$ \\
\hline Biodigestor & $193.944,58$ & $193.944,58$ \\
Motogerador & $148.617,00$ & $148.617,00$ \\
\hline Custos operacionais & $\mathbf{8 3 . 4 8 7 , 2 4}$ & $\mathbf{2 8 7 . 3 7 0 , 4 2}$ \\
\hline Manutenção do biodigestor & 969,72 & 969,72 \\
Manutenção do motogerador & $16.597,96$ & $18.453,64$ \\
Mão de obra (1 funcionário) & $30.844,80$ & $30.844,80$ \\
EPIs & 818,60 & 818,60 \\
Vinimanta superior (5o ano) & $77.577,83$ & $77.577,83$ \\
Desmobilização do sistema (10 ano) & $19.394,46$ & $19.394,46$ \\
Custo da aquisição do biorremediador & 0,00 & $202.027,50$ \\
\hline
\end{tabular}

SB- Sem biorremediador; CB- com biorremediador.

As receitas anuais referentes à geração de energia elétrica foram maiores que a receita proveniente da reciclagem dos nutrientes em todos os cenários, 37,43 e 36,19\%, para os cenários SB e CB1,0, respectivamente. Isso nos demonstra que a geração de energia elétrica é um fator determinante para viabilizar o projeto, e que, a busca por produtos que possibilitem aumentar a produção de biogás é essencial para promover a implantação de biodigestores no meio rural.

Os maiores potenciais de produção de biogás foram observados nos tratamentos que receberam a aplicação do biorremediador, consequentemente, os cenários econômicos que apresentaram as maiores receitas totais. No entanto, os custos operacionais dos dois projetos se diferem.

É possível observar que todos os cenários apresentam o mesmo custo total de investimento. O dimensionamento dos equipamentos (biodigestor e gerador) foram calculados com base no número de vacas e quantidade de resíduos gerados, que foi igual nos dois cenários, ou seja, os biodigestores tinham capacidade de $1000 \mathrm{~m}^{3}$ e o gerador uma potência de 50kVA. Porém, os custos operacionais totais variaram em cada cenário de acordo com a utilização do biorremediador. Por isso, que com a aplicação do biorremediador, houve um aumento expressivo nos custos totais dos projetos CB.

A quantidade de biorremediador estimada para o cenário CB foi de $109,5 \mathrm{Kg}^{-1}$ ano, o que gerou custos a mais de $\mathrm{R} \$ 202.027,50$ por ano, de acordo com o valor comercial do produto, quando comparados aos custos do cenário SB.

A partir da análise tradicional do fluxo de caixa descontado foram calculados o Valor Presente Líquido (VPL) e a Taxa Interna de Retorno (TIR) com a finalidade de verificar a viabilidade econômica para cada cenário avaliado. A tabela 9 apresenta os indicativos econômicos no horizonte de 10 anos, dos cenários estudados.

Tabela 9: Indicativos econômicos dos cenários avaliados

\begin{tabular}{lll}
\hline Cenários & Valor Presente líquido (R\$) & Taxa interna de retorno (\%) \\
\hline SB & $264.273,2$ & 18 \\
CB & $-1.126 .293,69$ & - \\
\hline
\end{tabular}

SB- Sem biorremediador; CB- com biorremediador. 
Os resultados demonstram que o cenário SB, foi o único viável economicamente. A inviabilidade econômica observada no cenário CB é decorrente do custo adicional do biorremediador utilizado para aumentar a produção de biogás. Com isso, pode-se constatar que o produto não apresenta um bom custo/benefício para ser utilizado nestas proporções, com dejetos de 200 vacas, para aumentar a produção de energia elétrica na propriedade rural.

A partir da análise do fluxo de caixa descontado, quando consideramos os resultados do indicador econômico VPL (Tabela 9), correspondentes aos cenários com a aplicação do biorremediador, observamos valores negativos, o que indica que a aplicação do produto não foi economicamente viável.

No entanto, o cenário $C B$ apresentou os maiores potenciais de produção de biogás no ensaio semicontínuo, o que demostra a eficácia técnica na melhoria do processo de digestão anaeróbia do dejeto de bovinos leiteiros para aumentar a produção de biogás. Contudo, a sua utilização só será viável ao produtor rural, caso o produto seja oferecido a um preço mais competitivo e reduzido no mercado, tornando assim o projeto economicamente viável.

Desse modo, o projeto terá condições de atender não só a disposição adequada dos dejetos bovinos, tornando-o fonte de energia renovável, mas também proporcionará uma relação favorável entre os aspectos econômico e ambiental (SILVA et al., 2019).

\section{CONCLUSÕES}

A aplicação isolada dos fatores amido e biorremediador apresenta efeito positivo, fato que mostra ser possível a aplicação direta desses aditivos e assim a vantagem de eliminar a aquisição de equipamentos auxiliares e seus custos operacionais com o emprego da aplicação desses aditivos como técnica de prétratamento.

A aplicação do biorremediador em conjunto ao amido, simulando a técnica de codigestão do dejeto de bovinos com culturas energéticas amiláceas, não resultou melhorias técnicas em relação a produção de biogás devido a biodegradabilidade natural apresentada pelo amido. A dose de interesse de viabilidade técnica de 1,0 mL, no entanto, não correspondeu positivamente a análise de viabilidade econômica, o que leva necessidade do seu preço comercial ser ajustado.

Análise de Componentes Principais apresentou o agrupamento dos tratamentos com a aplicação direta dos aditivos correlacionados com as variáveis de potencias de produção por biogás e metano, além das reduções de sólidos assegurando a possibilidade de se melhorar a DA de dejetos bovinos, mesmo após pré-tratamento mecânico.

\section{REFERÊNCIAS}

ANEEL. Agência Nacional de Energia Elétrica. Tarifa Média por Classe de Consumo e por Região. ANEEL, 2020.

ANGELIDAKI, I.; BOE, K.; ELLEGAARD, L.. Effect of operating conditions and reactor configuration on efficiency of fullscale biogas plants. Water Science and Technology, v.52, n.1-2, p.189-194, 2005. DOI: https://doi:10.2166/wst.2005.0516

APHA. American Public Health Association. Standart methods for the examination of water and wastewater. 20 ed. Washington: APHA, 2005.

BRÉMOND, U.; BUYER, R.; STEYER, J. P.; BERNET, N.; 
CARRERE, H.. Biological pretreatments of biomass for improving biogas production: an overview from lab scale to full-scale. Renewable and Sustainable Energy Reviews, v.90, p.583-604, 2018. DOI:

http://dx.doi:10.1016/j.rser.2018.03.103

BRIJWANI, K.; OBEROI, H. S.; VADLANI, P. V.. Production of a cellulolytic enzyme system in mixed-culture solid-state fermentation of soybean hulls supplemented with wheat bran. Process Biochemistry, v.45, n.1, p.120-128, 2010. DOI: http://dx.doi.org/10.1016/j.procbio.2009.08.015

BRUNI, E.; JENSEN, A. P.; ANGELIDAKI, I.. Steam treatment of digested biofibers for increasing biogas production. Bioresource Technology, v.101, n.19, p.7668-7671, 2010. DOI: http://dx.doi:10.1016/j.biortech.2010.04.064

CAMMAROTA, M. C.; FREIRE, D. M. G.. A review on hydrolytic enzymes in the treatment of wastewater with high oil and grease content. Bioresource Technology, v.97, n.17, p.2195-2210, 2006.

DOI: http://dx.doi:10.1016/j.biortech.2006.02.030

CHEN, Z.; ZHANG, W.; YANG, L.; STEDTFELD, R. D.; PENG, A.; GU, C.; BOYD, S. S.; LI, H.. Antibiotic resistance genes and bacterial communities in cornfield and pastures soils receiving swine and dairy manures. Environmental Pollution, Barking, v.248, p.947-957, 2019. DOI: http://dx.doi.10.1016/i.envpol.2019.02.093

CHERNICHARO, C. A. L.. Reatores Anaeróbios: Princípios do Tratamento Biológico de Águas Residuárias. 2 ed. Belo Horizonte: UFMG, 2007.

COSTA, L. V.; MOGHRABI, J. A.; SAGULA, A. L.; JUNIOR, J. L. Tratamento anaeróbico da água residuária de frigorífico com uso de biodigestores: utilização de remediadores biológicos para produção de biogás. Brazilian Journal of Biosystems Engineering, Tupã, v.7, n.2, p.77-85, 2013.

DONOSO-BRAVO, A.; FDZ-POLANCO, M.. Anaerobic codigestion of sewage sludge and grease trap: Assessment of enzyme addition. Process Biochemistry, v.48, n.5-6, p.936940, 2013. DOI: http://dx.doi:10.1016/j.procbio.2013.04.005

GABALLAH, E. S.; EL-FATAH A. A.; XU, C.; ELSAYED, M.; ABDELKADER, T. K. H.; LIN, J.; YUAN, Q.. Enhancement of biogas production from rape straw using different copretreatment techniques and anaerobic co-digestion with cattle manure. Bioresource Technology, v.309, p.123311, 2020. DOI:

http://dx.doi.org/:10.1016/j.biortech.2020.123311

GARCIA, N.H.; BENEDETTI, M.; BOLZONELLA, D.. Effects of enzymes addition on biogas production from anaerobic digestion of agricultural biomasses. Waste and Biomass Valorization, v.10, n.12, p.3711-3722, 2019. DOI: http://dx.doi:10.1007/s12649-019-00698-7

GERHARDT, M.; PELENC, V.; BÄUML, M.. Application of hydrolytic enzymes in the agricultural biogas production: Results from practical applications in Germany. Biotechnology Journal, v.2, n.12, p.1481-1484, 2007. DOI: http://dx.doi:10.1002/biot.200700220

GRAHAM, J. R.; HARVEY, C. R.. The theory and practice of corporate finance: Evidence from the field. Journal of
Financial Economics, v.60, n.2-3, p.187-243, 2001.

HÖLKER, U.. Was leisten Zusatzstoffe \& Hilfsmittel zur Optimierung der Biogasproduktion. Gülzower Fachgespräch Tagungsband Biogas inder Landwirtschaft - Stand und Perspektiven, v.32, p.108-119, 2009.

IMENI, S. M.; PUY, N.; OVEJERO, J.; BUSQUETS, A. M.; BARTROLI, J.; PELAZ, L.;COLÓN, J.. Techno-economic assessment of anaerobic co-digestion of cattle manure and wheat straw (raw and pre-treated) at small to medium dairy cattle farms. Waste Biomass Valor, v.11, n.8, p.4035-4051, 2020. DOI: http://dx.doi:10.1007/s12649-019-00728-4

KAISER, H. F.. The varimax criterion for analytic rotation in factor analysis. Psychometrika, v.23, n.3, p.187-200, 1958.

KALAMARAS, S. D.; KOTSOPOULOS, T. A.. Anaerobic codigestion of cattle manure and alternative crops for the substitution of maize in South Europe. Bioresource Technology, n.172, p.68-75,2014. DOI: http://dx.doi:10.1016/i.biortech.2014.09.005

KAUFMANN, T.. Sustainable livestock production: Low emission farm: the innovative combination of nutrient, emission and waste management with special emphasis on Chinese pig production. Animal Nutrition, v.1, n.3, p.104112, 2015. DOI: http://dx.doi:10.1016/j.aninu.2015.08.001

MAGDALENA, J.; BALLESTEROS, M.; GONZÁLEZ-FERNANDEZ, C.. Efficient anaerobic digestion of microalgae biomass: proteins as a key macromolecule. Molecules, v.23, n.5, p.1098, 2018. DOI:

http://dx.doi:10.3390/molecules23051098

MALAVOLTA, E.; VITTI, G. C.; OLIVEIRA, S. A.. Avaliação do estado nutricional das plantas: princípios e aplicações. Piracicaba. Associação Brasileira para Pesquisa da Potassa e do Fosfato. 2 ed. Piracicaba, 1997. p.115-230.

MARAÑÓN, E.; CASTRILLÓN, L.; QUIROGA, G.; FERNÁNDEZNAVA, Y.; GÓMEZ, L.; GARCÍA, M. M.. Co-digestion of cattle manure with food waste and sludge to increase biogas production. Waste Management, v.32, n.10, p.1821-1825, 2012. DOI: http://dx.doi.org:10.1016/j.wasman.2012.05.033

MONTORO, S. B.; LUCAS, J.; SANTOS, D. F. L.; COSTA, M. S. S. M.. Anaerobic co-digestion of sweet potato and dairy cattle manure: A technical and economic evaluation for energy and biofertilizer production. Journal of Cleaner Production, v.226, p.1082-1091, 2019. DOI: http://dx.doi.org/10.1016/j.jclepro.2019.04.148

NESHAT, S. A.; MOHAMMADI, M.; NAJAFPOUR, G. D.; LAHIJANI, P.. Anaerobic co-digestion of animal manures and lignocellulosic residues as a potent approach for sustainable biogas production. Renewable and Sustainable Energy Reviews, v.79, p.308-322, 2017. DOI: http://dx.doi:10.1016/j.rser.2017.05.137

PERAZZOLI, M.; KUNZE, M. A. B.. Gestão ambiental aplicada em uma propriedade rural com atividade de bovinocultura de corte. Revista Gestão e Sustentabilidade Ambiental, Florianópolis, v.7, n.4, p.704-717, 2018.

PRAES, M. F. F. M.; LUCAS JUNIOR, J.; ORRICO, A. C. A.; ORRICO JUNIOR, M. A. P.; HERMES, R. G.; SORBARA, J. O. B.; 
DUARTE, K. F.; SCHWINGEL, A. W.; SGAVIOLI, S.; DOMINGUES, C. H. F.; SUNADA, N. S.. Biogas production: litter from broilers receiving direct-fed microbials and an enzyme blend. Scientia Agricola, v.73, n.5, p.406-411, 2015. DOI: https://doi.org/10.1590/0103-9016-2015-0195

REGERT, R.; BORGES JÚNIOR, G. M.; BRAGAGNOLO, S. M.; BAADE, J. H.. Importância dos indicadores econômicos, financeiros e de endividamento como gestão do conhecimento na tomada de decisão em tempos de crise. Visão, Caçador, v.7, n.2, p.67-83, 2018.

ROCHA, D. T.; RESENDE, J. C.; MARTINS, P. C.. Evolução tecnológica da atividade leiteira no Brasil: Uma visão a partir do Sistema de Produção da Embrapa Gado de Leite. Juiz de Fora: Embrapa Gado de Leite, 2018.

ROMANO, R. T.; ZHANG, R.; TETER, S.; MCGARVEY, J. A.. The effect of enzyme addition on anaerobic digestion of Jose Tall Wheat Grass. Bioresource Technology, v.100, n.20, p.45644571, 2009. DOI:

http://dx.doi:10.1016/i.biortech.2008.12.065

GÜIZA, M. S. R.; MATA-ALVAREZ, J.; VILA, J. M.; CHIMENOS, S.. Astals The role of additives on anaerobic digestion: $A$ review. Renewable and Sustainable Energy Reviews, v.58, p.1486-1499, 2016. DOI:

http://dx.doi:10.1016/j.rser.2015.12.094

SCARLAT, N.; DALLEMAND, J-F.; FAHL, F.. Biogas: Developments and perspectives in Europe. Renewable

Energy, v.129, p.457-472, 2018. DOI:

http://dx.doi:10.1016/j.renene.2018.03.006

ŞENOL, H.; AÇIKEL, Ü.; DEMIR, S.; ODA, V.. Anaerobic digestion of cattle manure, corn silage and sugar beet pulp mixtures after thermal pretreatment and kinetic modeling study. Fuel, v.263, n.116651, 2019. DOI: http://dx.doi:10.1016/j.fuel.2019.116651

SILVA, J. R.; ASSUMPÇÃO, R.; VEGRO, C. L. R.. A inserção da fécula de mandioca no mercado de amido. Informações econômicas, v.30, n.7, p.31-41, 2000.
SILVA, A. C. G.; TREVISAN, G. M.. Processo de produção e aproveitamento energético do biogás: uma revisão dos sistemas e tecnologias existentes no mercado. Revista lberoAmericana de Ciências Ambientais, v.10, n.2, p.197-210, 2019. DOI: http://doi.org/10.6008/CBPC2179$\underline{6858.2019 .002 .0017}$

SPEDA, J.; JOHANSSON, M. A.; ODNELL, A.; KARLSSON, M. Enhanced biomethane production rate and yield from lignocellulosic ensiled forage ley by in situ anaerobic digestion treatment with endogenous cellulolytic enzymes. Biotechnology for Biofuels, v.10, n.1, 2017. DOI: http://dx.doi:10.1186/s13068-017-0814-0

TEGHAMMAR, A.; KARIMI, K.; SÁRVÁRI HORVÁTH, I.; TAHERZADEH, M. J.. Enhanced biogas production from rice straw, triticale straw and softwood spruce by NMMO pretreatment. Biomass and Bioenergy, v.36, p.116-120, 2012. DOI: http://dx.doi:10.1016/j.biombioe.2011.10.019

VIEIRA, A. D.; MIRANDA, V. C.; ALVES, A. F.; TAVARES, A. T.. Avaliação agronômica de clones de batata doce com potencial para produção de etanol. Revista Brasileira de Tecnologia Aplicada nas Ciências Agrárias, Guarapuava, v.8, n.1, p.69-74, 2015. DOI:

http://dx.doi:.10.5935/PAeT.V8.N1.08

ZHANG, L.; LOH, K.-C.; ZHANG, J..Enhanced biogas production from anaerobic digestion of solid organic wastes: Current status and prospects. Bioresource Technology Reports, v.5, p.280-296, 2018. DOI: http://dx.doi:10.1016/j.biteb.2018.07.005

ZHENG, Y.; ZHAO, J.; XU, F.; LI, Y.. Pretreatment of lignocellulosic biomass for enhanced biogas production. Progress in Energy and Combustion Science, v.42, p.35-53, 2014. DOI: http://dx.doi:10.1016/j.pecs.2014.01.001

ZULKIFLI, Z.; ISMAIL, S. B.; ZAHARI, M. S. M.; UMOR, N. A.; $A Z I Z, N$ N. I. A.. Screening on biogas optimization of lignocellulose-based materials using enzymatic hydrolysis process. Chemical Engineering Transactions, v.45, p.15851590, 2015. DOI: http://dx.doi10.3303/CET1545265

A CBPC - Companhia Brasileira de Produção Científica (CNPJ: 11.221.422/0001-03) detém os direitos materiais desta publicação. Os direitos referem-se à publicação do trabalho em qualquer parte do mundo, incluindo os direitos às renovações, expansões e disseminações da contribuição, bem como outros direitos subsidiários. Todos os trabalhos publicados eletronicamente poderão posteriormente ser publicados em coletâneas impressas sob coordenação da Sustenere Publishing, da Companhia Brasileira de Produção Científica e seus parceiros autorizados. Os (as) autores (as) preservam os direitos autorais, mas não têm permissão para a publicação da contribuição em outro meio, impresso ou digital, em português ou em tradução. 